\title{
Host response, malnutrition and oral diseases. Part 2
}

\author{
SYLWIA MAEGORZATA SŁOTWINSSKA ${ }^{l}$, ROBERT SŁOTWIŃSKR ${ }^{2,3}$
}

${ }^{1}$ Department of Conservative Dentistry, Medical University of Warsaw, Poland

${ }^{2}$ Department of Immunology, Biochemistry and Nutrition, Medical University of Warsaw, Poland

${ }^{3}$ Department of Surgical Research and Transplantology, Mossakowski Medical Research Center, Polish Academy of Sciences, Warsaw

\begin{abstract}
Acute phase proteins enhance antioxidant defenses; they are involved in the activation of complement components, opsonization and increase in platelet aggregation as well as inhibition of the respiratory burst in the course of inflammation. Malnutrition plays an important role in the course of response of acute phase proteins. The role of nutrients as antioxidants or as key components of antioxidant enzymes is commonly known. In the course of various inflammatory states, including oral diseases, disorders are observed in caloric requirements of the organism and the requirements for specific amino acids. Numerous experimental studies in animals have also confirmed the relationship between protein-calorie malnutrition and hypofunction of the salivary glands. Studies in children with malnutrition syndrome showed a significantly lower volume of saliva compared to properly nourished children. Depleted nutritional reserves due to long-term chronic malnutrition cause a significant reduction in resistance, progressive damage to the oral mucosa, and reduce resistance to colonization and invasion of pathogenic microorganisms.
\end{abstract}

Key words: malnutrition, host response, oral diseases.

(Centr Eur J Immunol 2014; 39 (4): 522-524)

Malnutrition plays an important role in the course of response of acute phase proteins - the body's non-specific response to tissue damage, which is characterized by increased temperature, elevated number of peripheral leukocytes, hormonal changes and disorders in the process of liver protein synthesis [1]. The reaction of acute phase proteins is also observed in the course of periodontal diseases. Of course, its severity depends on the advancement of inflammation and the degree of tissue damage. Acute phase proteins enhance antioxidant defenses, and they are involved in the activation of complement components, opsonization and increase in platelet aggregation as well as inhibition of the respiratory burst in the course of inflammation (amyloid A). The response of acute phase proteins in the case of infection is severely impaired even in children suffering from mild malnourishment, which has an important prognostic implication for tissue healing [2].

Similarly, in rats chronically maintained on a diet poor in protein, there is a significant weakening of acute phase protein response in the case of injury, as assessed by analysis of peripheral blood concentration of $\alpha_{2}$-macroglobulin, which is the main acute phase protein and a wide spectrum protease inhibitor in rats. The maximum value of $\alpha_{2}$-macroglobulin in protein-deficient rats was only at a level of $44 \%$ of the value observed in the group of control animals, while on the first day after the damage; it merely amounted to $14 \%$ of the value in the control animals [3].

The results of the studies on the weak reaction of acute phase proteins in malnutrition are comparable with impaired synthesis of cytokines, which obviously is not surprising, since cytokines, particularly interleukin (IL)-1 and IL- 6 , are the main mediators of acute phase protein synthesis.

In the course of various inflammatory states, including periodontal diseases, disorders are observed in caloric requirements of the organism and the requirements for specific amino acids, especially those related metabolically, i.e. glycine, serine, methionine and cysteine. The level of amino acids in the protein-calorie malnutrition with coexisting inflammation is drastically lowered, and in parallel, the demand is increasing for amino acid that is irrelevant to a healthy human diet, with a simple structure, i.e. glycine, which constitutes $34 \%$ of the amino acid residues in the collagen, the basic building material of periodontal structures. The level of cysteine, an amino acid functionally associated with regulation of the activity of lymphocytes, is also markedly decreased. Experimental studies in rats maintained on a low-protein diet showed that dietary supplementation with cysteine and glycine modulates the metabolic response to tumor necrosis factor $\alpha$ (TNF- $\alpha$ ) [4]. 
The role of nutrients as antioxidants or as key components of antioxidant enzymes is commonly known. The activity of antioxidant enzymes is considerably weakened during protein deficiency. The balance between the interaction of reactive metabolites of oxygen determines the ability of phagocytes to damage the periodontal tissue. There is a clear depletion of the key nutrient antioxidants observed in tissues in protein-calorie malnutrition as well as in other forms of malnutrition in humans, that involves e.g. zinc, $\alpha$-tocopherol, $\beta$-carotene, ascorbic acid and glutathione. The latter is present in normally functioning cells at a concentration of $0.5-10 \mathrm{mmol} / \mathrm{l}$ and is responsible for $>90 \%$ of non-protein thiols in the cell. It is also the main cell antioxidant and an important modulator of cytotoxic T-lymphocyte activation. In addition, glutathione is necessary for the synthesis of leukotrienes, important mediators in the course of periodontitis [5-7].

A significant increase in the concentration of histamine in tissues is observed in malnutrition, particularly protein-calorie malnutrition, and deficiency of ascorbic acid. Ascorbic acid has an important function in the detoxification of histamine in a variety of stress conditions. There is a marked increase in the concentration of histamine in the blood when the concentration of vitamin $\mathrm{C}$ in human serum decreases significantly below $0.7 \mathrm{mg} / 100$ $\mathrm{mg}$. Persistent high levels of endogenous histamine in the peripheral blood in the course of malnutrition causes hyperemia, and increased capillary permeability as well as decreased chemotaxis of neutrophils. Studies on the effects of controlled deficiency and supplementation of ascorbic acid on the periodontium condition have shown that although the depletion of vitamin $\mathrm{C}$ is not associated with severe periodontal disease, the degree of gingivitis and bleeding severity varies in relation to changes in the concentration of ascorbate in leukocytes and peripheral blood serum. A sudden decline in ascorbic acid concentration in peripheral blood leukocytes results in worse chemotaxis and inhibition of oxidative destruction of microorganisms as well as the neutralization of metabolic products of microbial organisms. The study on bactericidal activity of neutrophils in guinea pigs suffering from scurvy found that neutrophils contained 16 times less ascorbate than the control leukocytes and killed only $12 \%$ of phagocyted actinomycetes and additionally showed no chemotactic response in vitro [8-11].

There is a partial adaptation of secretion and hormonal function in the protein-calorie malnutrition and other forms of malnutrition that involves reduction in the synthesis of insulin, estrogens, androgen and triiodothyronine, while the production of growth hormone, cortisol, and reverse triiodothyronine is increased. Elevated levels of peripheral blood glucocorticoids inhibit the immune and inflammatory response, hinder wound healing processes and block the production of bone matrix and collagen synthesis as well as mitotic activity of gingival epithelium $[12,13]$. Higher levels of glucocorticoids in the peripheral blood not only stimulate muscle proteolysis and production of acute phase proteins, but also inhibit the secretion of cytokines by macrophages. The reduced insulin production in combination with an increased blood glucose concentration impairs the absorption of ascorbic acid, which can be an alternative for explaining the high incidence of severe periodontal disease in diabetes $[14,15]$.

Periodontal disease of severe course often coexists with HIV infection, and the majority of immune dysfunctions in the case of protein-calorie malnutrition and deficiency of specific, essential nutrients resembles changes observed in people diagnosed with human immunodeficiency virus (HIV) or an acquired immunodeficiency syndrome (AIDS). A reverse ratio of CD4+/CD8+ lymphocytes (below the value of 1 ) is observed both in the serum of people with protein-calorie deficiencies as well as in the peripheral circulation in patients suffering from AIDS, and topically in severe periodontitis $[16,17]$.

Diseases of the oral mucosa are another important issue in the field of malnutrition, especially protein-calorie malnutrition. Malnutrition increases the severity of infection of the oral cavity and contributes to the development of life-threatening diseases such as noma (cancrum oris) - gangrene of the mouth and face. Furthermore, it contributes to the formation of ulcers and erosions, glossitis, cheilitis and angular cheilitis as well as atrophy of salivary glands $[18,19]$.

Oral cancer is the eighth most common cancer in the world and exists both in developing and in some developed countries, such as Denmark, Germany, Scotland, and also in Eastern Europe [20]. It is believed that the deficiency of nutrients containing iron, selenium, $\beta$-carotene and vitamin A, B, C, E and vitamin B group is one of the risk factors for oral cancer [21, 22].

Numerous experimental studies in animals have also confirmed the relationship between protein-calorie malnutrition and hypofunction of the salivary glands. These works have found a decreased weight of the submandibular gland, reduced salivary flow and a lower concentration of proteins in the saliva of malnourished animals [23, 24]. In experimental rats, the levels of total protein, lysozyme, lactoperoxidase, and immunoglobulins were usually significantly reduced under conditions of malnutrition [25, 26]. There is a limited number of studies that have analyzed malnutrition and hypofunction of the salivary glands in humans. The studies primarily concerned children from poor countries [27, 28]. Studies in children with malnutrition syndrome showed a significantly lower volume of saliva compared to properly nourished children [29]. In another study in children suffering from malnutrition, lack of proper diet caused a significant reduction in stimulated salivary flow in conjunction with a reduction in buffer properties of saliva [30]. These studies indicated the possibility of a connection between protein-calorie malnutrition, salivary flow, buffer capacity and the protein composition/protein content in saliva. This type of function constraint may in- 
crease the risk of teeth caries and partially explains the relationship between caries and protein-calorie malnutrition.

In summary, host defense mechanisms are divided into specific, i.e. resulting from the function of the immune system, and non-specific that involve mucosal anatomical barriers, saliva and mucus secretion as well as synthesis of lysozymes, cytokines and acute phase proteins. Depleted nutritional reserves due to long-term chronic malnutrition cause a significant reduction in resistance, progressive damage to the oral mucosa, and reduced resistance to colonization and invasion of pathogenic microorganisms [31, 32]. The host response to infection also depends on the prior immune status, preceding the state of malnutrition. Adequate nutrition is not only an essential condition for the proper development and functioning of the human body, but also an important element in the prevention of oral diseases and an important factor in delaying and/or mitigation of already existing lesions.

\section{The authors declare no conflict of interest.}

\section{References}

1. Koj A (2010): Białka ostrej fazy - po 25 latach. Diagnostyka Laboratoryjna 46: 9-14.

2. Doherty JF, Golden MH, Raynes JG, et al. (1993): Acutephase protein response is impaired in severely malnourished children. Clin Sci 84: 169-175.

3. Jennings G, Elia M (1991): Independent effects of protein and energy deficiency on acute-phase protein response in rats. Nutrition 7: 430-434.

4. Grimble RF, Jackson AA, Persaud C, et al. (1992): Cysteine and glycine supplementation modulate the metabolic response to tumor necrosis factor $\alpha$ in rats fed a low protein diet. J Nutr 122: 2066-2073.

5. Huang CJ, Fwu ML (1993): Degree of protein deficiency affects the extent of the depression of the antioxidative enzyme activities and the enhancement of tissue lipid peroxidation in rats. J Nutr 123: 803-810.

6. Schaible UE, Kaufmann SH (2007): Malnutrition and infection: complex mechanisms and global impacts. PLoS Med 4: 806-812.

7. Jackson AA (1986): Blood glutathione in severe malnutrition in childhood. Trans R Soc Trop Med Hyg 80: 911-913.

8. Leggott PJ, Robertson PB, Rothman DL, et al. (1986): The effect of controlled ascorbic acid depletion and supplementation on periodontal health. J Periodontol 57: 480-485.

9. Staudte H, Kranz S, Völpel A, et al. (2012): Comparison of nutrient intake between patients with periodontitis and healthy subjects. Quintessence Int 43: 907-916.

10. Washko P, Rotrosen D, Levine M (1991): Ascorbic acid in human neutrophils. Am J Clin Nutr 54 (6 Suppl): 1221S-1227S.

11. Goldschmidt MC (1991): Reduced bactericidal activity in neutrophils from scorbutic animals and the effects of ascorbic acid on these target bacteria in vivo and in vitro. Am J Clin Nutr 54 (6 Suppl): 1214S-1220S.

12. Harpenau LA, Cheema AT, Zingale JA, et al. (2011): Effects of nutritional supplementation on periodontal parameters, carotenoid antioxidant levels, and serum C-reactive protein. J Calif Dent Assoc 39: 309-312.

13. Thomas B, Kumari S, Ramitha K, Ashwini Kumari MB (2010): Comparative evaluation of micronutrient status in the serum of diabetes mellitus patients and healthy individuals with periodontitis. J Indian Soc Periodontol 14: 46-49.

14. Mealey BL (2006): Periodontal disease and diabetes. A twoway street. J Am Dent Assoc 137 (10 Suppl): 26S-31S.

15. Gokhale NH, Acharya AB, Patil VS, et al. (2013): A short-term evaluation of the relationship between plasma ascorbic acid levels and periodontal disease in systemically healthy and type 2 diabetes mellitus subjects. J Diet Suppl 10: 93-104.

16. Rwenyonyi CM, Kutesa A, Muwazi L, et al. (2011): Oral manifestations in HIV/AIDS-infected children. Eur J Dent 5: 291-298.

17. Maddi A, Scannapieco FA (2013): Oral biofilms, oral and periodontal infections, and systemie disease. Am J Dent 26: 249-254.

18. Thomas DM, Mirowski GW (2010): Nutrition and oral mucosal disease. Clin Dermatol 28: 426-431.

19. Enwonwu CO, Falkler WA, Idigbe EO (2000): Oro-facial gangrene (noma/cancrum oris): pathogenetic mechanisms. Crit Rev Oral Biol Med 11: 159-171.

20. Petersen PE (2003): The World Oral Health Report 2003. Community Dent Oral Epidemiol 31 (1 Suppl): 3-24.

21. Enwonwu CO, Meeks VI (1995): Bionutrition and oral cancer in humans. Crit Rev Oral Biol Med 6: 5-17.

22. Barrios R, Tsakos G, García-Medina B, et al. (2014): Oral health-related quality of life and malnutrition in patients treated for oral cancer. Support Care Cancer 22: 2927-2933. doi: 10.1007/00520-014-2281-5 Epub.

23. Menaker L, Navia JM (1974): The effect of undernutrition during the perinatal period on caries development in the rat, changes in whole saliva volume and protein content. J Dent Res 53: 592-597.

24. Menaker L, Navia JM (1973): Effects of undernutrition during the perinatal period on caries development in the rat III. Effects of undernutrition on biochemical parameters in the developing submandibular salivary gland. J Dent Res 52: 688-691.

25. Johansson I, Ericson T, Bowen W, Cole M (1985): The effect on malnutrition on caries development and saliva composition in rat. J Dent Res 64: 37-43.

26. Deichtman GC, Antal M, Watson JG (1980): Concentrations of immunoglobulin $\mathrm{G}$ and amylase in saliva of moderately undernourished rats. J Food Sci 45: 1092-1095.

27. Agarwal PK, Agarwal KN, Agarwal DK (1984): Biochemical changes in saliva in malnourished children. Am J Clin Nutr 39: 181-184.

28. Azzopardi D, Watson JG (1986): Gambian children have less salivary secretory immunoglobulin A than British children. J Trop Pediatr 32: 120-122.

29. Johansson I, Lenander-Lumikari M, Saellström AK (1994): Saliva composition in Indian children with chronic protein-energy malnutrition. J Dent Res 73: 11-19.

30. Johansson I, Saellström AK, Rajan BP, Parameswaran A (1992): Salivary flow in dental caries in Indian children suffering from chronic malnutrition. Caries Res 26: 38-43.

31. Jontell M, Linde A (1986): Nutritional aspects on tooth formation. World Rev Nutr Diet 48: 114-136.

32. Tomkins A (2002): Nutrition, Infection and Immunity: Public Health Implications. In: Nutrition and Immune Function. Calder PC, Field CJ, Gill HS (eds.). CAB International Publishing, New York 2002; 375-412. 